\title{
Comparison of conservative therapy and steroid therapy for Bell's palsy in children
}

Hye Won Yoo, MD', Lira Yoon, MD', Hye Young Kim, MD, PhD', Min Jung Kwak, MD, PhD', Kyung Hee Park, MD', Mi Hye Bae, MD', Yunjin Lee, MD, PhD², Sang Ook Nam, MD, PhD², Young Mi Kim, MD, PhD'

'Department of Pediatrics, Pusan National University Hospital, Pusan National University School of Medicine and Biochemical Research Institute, Busan, ${ }^{2}$ Department of Pediatrics, Pusan National University Yangsan Hospital, Pusan National University School of Medicine and Biochemical Research Institute, Yangsan, Korea

Purpose: Bell's palsy is characterized by sudden onset of unilateral facial weakness. The use of corticosteroids for childhood Bell's palsy is controversial. This study aimed to identify clinical characteristics, etiology, and laboratory findings in childhood Bell's palsy, and to evaluate the efficacy of corticosteroid treatment.

Methods: We conducted a retrospective analysis of children under 19 years of age treated for Bell's palsy between January 2009 and June 2017, and followed up for over 1 month. Clinical characteristics, neuroimaging data, laboratory findings, treatments, and outcomes were reviewed. Patients with Bell's palsy were divided into groups with (group 1) and without (group 2) corticosteroid treatment. Differences in onset age, sex, laterality, infection and vaccination history, degree of facial nerve palsy, and prognosis after treatment between the groups were analyzed.

Results: One hundred patients were included. Mean age at presentation was $7.4 \pm 5.62$ years. A total of 73 patients (73\%) received corticosteroids with or without intravenous antiviral agents, and 27 (27\%) received only supportive treatment. There was no significant difference in the severity, laboratory findings, or neuroimaging findings between the groups. Significant improvement was observed in 68 (93.2\%) and 26 patients (96.3\%) in groups 1 and 2, respectively; this rate was not significantly different between the groups $(P=0.48)$.

Conclusion: Childhood Bell's palsy showed good prognosis with or without corticosteroid treatment; there was no difference in prognosis between treated and untreated groups. Steroid therapy in childhood Bell's palsy may not significantly improve outcomes.

Key words: Peripheral facial paralysis, Bell palsy, Child

\section{Introduction}

Acute peripheral palsy of the facial nerve is relatively common in children. Bell palsy is a disease manifesting as acute idiopathic peripheral facial nerve palsy. Facial nerve paralysis may induce facial asymmetry. The incidence of Bell's palsy in children varies from 5-21:100,000/ yr. ${ }^{1)}$ Acute peripheral facial palsy may be caused by infections, congenital disorders, systemic disorders, trauma, metabolic disorders, iatrogenic diseases, or neoplasms. However, in most cases of acute onset Bell's palsy in children, there is no known cause for the idiopathic peripheral facial palsy. ${ }^{2,3)}$ Overall, the prognosis of patients with Bell's palsy is excellent. Complete functional recovery usually occurs within 2 weeks of symptom onset.

In severe cases of Bell's palsy, the cornea may be at risk because of poor eye lid closure and reduced tearing. Therefore, artificial tears and blindfolds are used as conservative treatment to
Corresponding author: Young Mi Kim, MD, PhD Department of Pediatrics, Pusan National University Hospital, Pusan National University School of Medicine and Biochemical Research Institute, 179 Gudeok-ro, Seo-gu, Busan 49241, Korea

Tel: +82-51-240-7298

Fax: +82-51-248-6205

E-mail: pink2129@naver.com

https://orcid.org/0000-0002-4689-8974

Received: 2 March, 2018

Revised: 25 April, 2018

Accepted: 2 May, 2018
Copyright $(2018$ by The Korean Pediatric Society

This is an open-access article distributed under the terms of the Creative Commons Attribution NonCommercial License (http://creativecommons.org/ licenses/by-nc/4.0/) which permits unrestricted noncommercial use, distribution, and reproduction in any medium, provided the original work is properly cited. 
prevent eye dryness. The use of corticosteroid, alone or in combination with antiviral agents such as acyclovir or valacyclovir, has been reported to be effective in some cases of Bell's palsy; however, the efficacy of this treatment, especially in children, remains unclear. Steroids may reduce inflammation, neural edema, and nerve compression in the facial canal. ${ }^{4)}$ In adults, treatment with corticosteroid has been demonstrated to have significant benefits, especially if used early in the course of illness. ${ }^{5,6)}$

In contrast to adults, the natural course of Bell's palsy in children is not well documented. There is a relative lack of research on the incidence, etiology, treatment strategy, recovery period, and prognosis of Bell's palsy in children. The purpose of this study was to investigate the clinical characteristics and etiology of Bell's palsy, and to examine the efficacy of corticosteroid treatment by comparing the treated and nontreated groups retrospectively.

\section{Materials and methods}

\section{Patients}

Clinical records of children under 19 years of age diagnosed with Bell's palsy at Pusan National University Hospital between January 2009 and June 2017 were retrospectively reviewed. The criteria for inclusion were a diagnosis of acute peripheral facial nerve palsy, and a follow-up period lasting for at least 1 month. Patients meeting the following criteria were included this study: (1) diagnosed with idiopathic peripheral facial palsy, (2) followed up for at least 1 month, (3) no evidence of systemic diseases, (4) no previous history of facial palsy, and (5) no previous treatment with corticosteroid for facial palsy. Exclusion criteria were (1) facial palsy resulting from other causative conditions, such as congenital diseases, trauma, acute otitis media, and vascular lesions, (2) facial palsy accompanied by palsy of other cranial nerves, (3) previous treatment history, and (4) recurrent facial palsy. Patients with Bell's palsy were divided into 2 groups: one group received oral steroid treatment (group 1) and the other group did not receive this treatment (group 2). Patients and their parents were fully informed about the course and prognosis of the Bell's palsy, and steroid treatment was initiated if there was anxiety about prognosis or rejection of conservative treatment.

\section{Methods}

We conducted a retrospective review of electronic medical records. The following variables were reviewed: onset age, sex, infection and vaccination history, laterality, severity of facial palsy, laboratory findings, magnetic resonance imaging (MRI) findings, treatments, and outcomes. All patients were also examined by an otolaryngologist and an ophthalmologist during the initial work up. The differences in age, sex, laterality, infection or vaccination history, degree of facial nerve palsy, and prognosis after treatment between the groups were analyzed. The House-Brackmann score was used to classify the severity of facial palsy (Table 1). Severity improvement was defined as a decrease in the grade by 2 or more points, or the achievement of grade I. The Institutional Review Board (IRB) of Pusan National University Hospital approved this study (1810-002071). The requirement for informed patient consent was waived by the IRB.

\section{Statistical analysis}

Statistical analysis was conducted using IBM SPSS Statistics ver. 23.0 (IBM Co., Armonk, NY, USA) and was used to analyze the differences between the groups. Data are presented as means and standard deviations. The Fisher exact test was applied for analyzing categorical data, and the Mann-Whitney test was used for continuous variables. For all analyses, $P$ values $<0.05$ were considered statistically significant.

\section{Results}

\section{Demographics and clinical characteristics}

A total of 139 patients were diagnosed with facial palsy; however, 23 patients were excluded due to symptoms caused by congenital diseases, trauma, or acute otitis media, or because they had a previous treatment history. Of the remaining 116 patients, 16 patients were excluded due to follow-up loss. Finally, 100 patients were included in our study (Fig. 1). There was no sexual predilection. The mean age at onset was $7.4 \pm 5.62$ years ( \pm standard deviation), ranging from 2 months to 19 years. Demographic characteristics of the children with Bell's palsy, and their clinical findings, are shown in Table 2. Right peripheral facial palsies were found in 49 patients (49\%).

\section{Etiology}

Thirty-nine patients (39\%) had a previous history of infections, such as upper respiratory tract infection, herpangina, and hand-footand-mouth disease, within 4 weeks before palsy onset. A respiratory virus polymerase chain reaction (PCR) test were performed in 22 patients (22\%) and confirmed that 6 patients were infected with rhinovirus, 1 patient with adenovirus, and 1 patient with corona-

\begin{tabular}{ll}
\multicolumn{2}{l}{ Table 1. House-Brackmann facial paralysis scale } \\
\hline Grade & \multicolumn{1}{c}{ Description } \\
\hline II & Normal function \\
III & $\begin{array}{l}\text { Mild dysfunction. Complete eye closure. Normal symmetry at rest } \\
\text { rest }\end{array}$ \\
IV $\quad \begin{array}{l}\text { Moderate-to-severe dysfunction. Incomplete eye closure. Obvious } \\
\text { asymmetry }\end{array}$ \\
V $\quad \begin{array}{l}\text { Severe dysfunction. Incomplete eye closure. Only twitch observed in } \\
\text { gross motor movements }\end{array}$
\end{tabular}




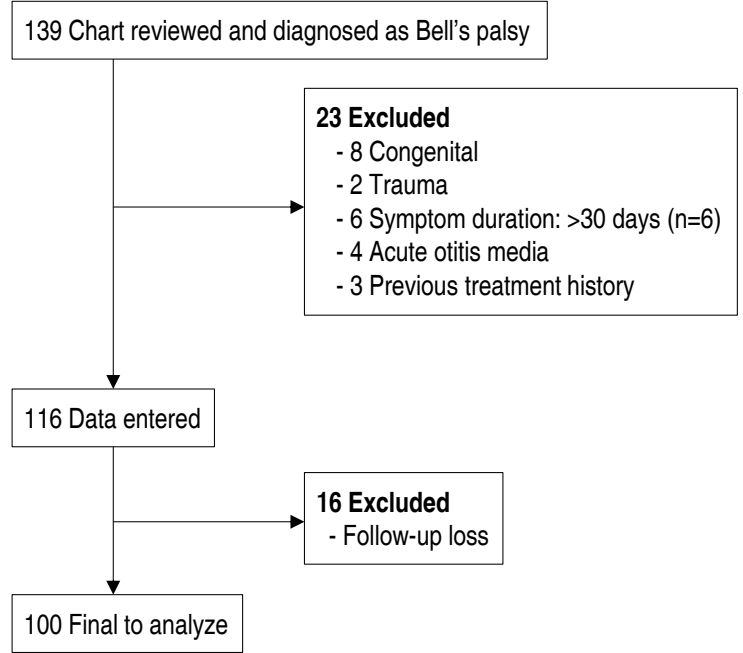

Fig. 1. Flow chart for patient selection.

Table 2. Demographic characteristics of patients with Bell's palsy $(\mathrm{n}=100)$

\begin{tabular}{|c|c|}
\hline Characteristic & Value \\
\hline Sex, male:female & $50: 50$ \\
\hline Age at diagnosis (yr) & $7.4 \pm 5.6$ \\
\hline \multicolumn{2}{|l|}{ Laterality } \\
\hline Right & $49(49)$ \\
\hline Left & $51(51)$ \\
\hline \multicolumn{2}{|l|}{ Severity } \\
\hline$\|$ & $19(19)$ \\
\hline III & $45(45)$ \\
\hline IV & $33(33)$ \\
\hline V & $3(3)$ \\
\hline History of infection within 4 weeks & $39(39)$ \\
\hline History of vaccination within 4 weeks & $5(5)$ \\
\hline \multicolumn{2}{|l|}{ Blood examination } \\
\hline Mild leukocytosis & $12(12)$ \\
\hline Positive for Epstein-Barr virus IgM ( $\mathrm{n}=31)$ & $7(22)$ \\
\hline Positive for Herpes simplex virus lgM ( $n=55)$ & $3(5)$ \\
\hline Positive for varicella zoster virus IgM ( $\mathrm{n}=51)$ & $4(7)$ \\
\hline \multicolumn{2}{|l|}{ Cerebrospinal fluid examination $(n=60)$} \\
\hline Pleocytosis & $2(3.3)$ \\
\hline \multicolumn{2}{|l|}{ Patients who underwent brain MRI ( $n=91)$} \\
\hline Normal & $51(56)$ \\
\hline Abnormal findings relevant to diagnosis & $29(31)$ \\
\hline Abnormal findings irrelevant to diagnosis & $11(12)$ \\
\hline \multicolumn{2}{|l|}{ Treatment } \\
\hline Steroid alone & $63(63)$ \\
\hline Steroid and antiviral agent & $10(10)$ \\
\hline None & $27(27)$ \\
\hline
\end{tabular}

Values are presented as mean \pm standard deviation or number (\%).

IG, immunoglobulin; MRl, magnetic resonance imaging. virus. The remaining patients did not show a positive result in the respiratory PCR test. Five of the patients under 1 year of age had received vaccinations, such as influenza or DTaP-IPV vaccine within 4 weeks before palsy onset. No fever or other symptoms were observed after vaccination in these patients. Of the patients who underwent blood examinations, 7 patients (22\%) tested positive for Epstein-Barr virus immunoglobulin (Ig) M, 3 patients (5\%) for Herpes simplex virus IgM, and 4 patients (7\%) for varicella zoster virus IgM. In the other patients, no known cause of the facial palsy was found.

\section{Seasonal variation}

Twenty-eight patients (28\%) presented with palsy in spring, 21 in summer, 26 in late fall, and 25 in winter. A seasonal variation in the frequency was not observed in our study (Fig. 2).

\section{Laboratory findings}

Blood serologic examinations were conducted in all patients within 7 days of palsy onset. Only 12 patients (12\%) showed mild leukocytosis (maximum 14,010 cells/ $\mu \mathrm{L}$ ). Abnormal findings, such as elevated levels of C-reactive protein or erythrocyte sedimentation rate, were not observed. Of the 60 patients (60\%) that underwent cerebrospinal fluid examination, only 2 patients (3.3\%) showed pleocytosis. Only one of them showed clinical sign of meningitis, such as headache, and received mannitol treatment $(1 \mathrm{~g} / \mathrm{kg} /$ day) under the diagnosis of viral meningitis.

\section{Severity}

The severity of facial palsy was classified using the HouseBrackmann grade. The numbers of patients with each grade are as follows: grade II, 19 patients (19\%); grade III, 45 patients (45\%); grade IV, 33 patients (33\%); grade V, only 3 patients (3\%). There was no significant difference in the severity at onset between the groups (Table 3).

\section{Treatment}

Sixty-three patients (63\%) were treated with corticosteroid alone. Ten patients (10\%) received an acyclovir (10 mg/kg, every 8 hours) treatment along with steroid. Twenty-seven patients (27\%) received

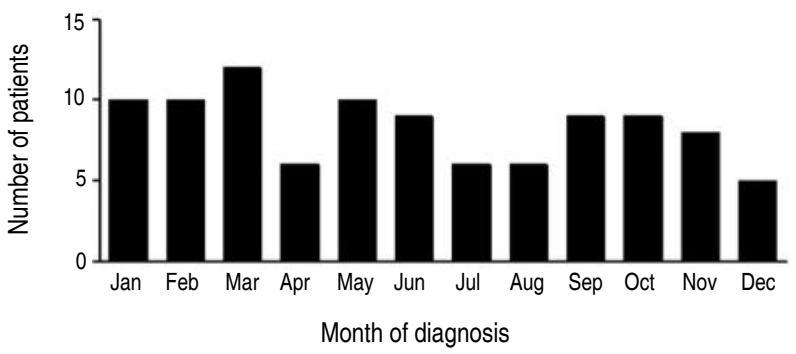

Fig. 2. Seasonal variation in the diagnosis of Bell's palsy. 
Table 3. Comparison of age, sex, and clinical outcomes between treated (group 1) and untreated (group 2) groups

\begin{tabular}{lcccc}
\hline Variable & $\begin{array}{c}\text { Total } \\
(\mathrm{n}=100)\end{array}$ & $\begin{array}{c}\text { Group 1 } \\
(\mathrm{n}=73)\end{array}$ & $\begin{array}{c}\text { Group 2 } \\
(\mathrm{n}=27)\end{array}$ & $P$ value* \\
\hline Mean age at diagnosis (yr) & 7.4 & 8.0 & 5.8 & 0.08 \\
Mean symptom to diagnosis (day) & 2.5 & 2.5 & 2.6 & 0.70 \\
Initial severity & & & & \\
II & 19 & 15 & 4 & 0.37 \\
III & 45 & 31 & 14 & 0.27 \\
IV & 33 & 26 & 7 & 0.25 \\
V & 3 & 1 & 2 & 0.18 \\
Mean duration of follow-up (mo) & 2.0 & 2.0 & 2.0 & 0.55 \\
Mean severity improvement & 2.0 & 2.0 & 2.1 & 0.55 \\
Outcome & & & & \\
$\quad$ Good, $n$ (\%) & $94(94)$ & $68(93.2)$ & $26(96.3)$ & 0.48 \\
\hline
\end{tabular}

*Fisher exact test or Mann-Whitney test was performed.

only supportive treatments with artificial tears. Oral prednisolone (1 $\mathrm{mg} / \mathrm{kg} /$ day up to $60 \mathrm{mg} /$ day) was administered to the treated group (group 1) for 7 days, and was gradually tapered for the following 7 days. No adverse effects due to steroid treatment were reported.

There was no significant difference in the mean onset age, the duration from symptom onset to diagnosis, severity, and the duration of follow-up between groups 1 and 2. The outcomes in groups 1 and 2 patients are presented in Table 3 . The improvement in the severity grade and the rate of good outcomes did not significantly differ between groups 1 and 2 .

\section{Magnetic resonance imaging}

In Korea, many people perceive facial palsy as a type of stroke, as a “Wasapung” or “Guanwasa (口眼喎斜) traditionally and are very nervous about it. The caregivers wanted to confirm the absence of any abnormalities. Therefore, we have given enough explanation and then proceeded with the MRI after obtaining consent. Brain MRI was performed in 91 patients (91\%) with Bell's palsy. Twenty-nine patients (31\%) with Bell's palsy showed abnormal MRI findings, that is, thickening and/or enhancement of the facial nerve (Table 2). Eleven patients (12\%) were found to have MRI abnormalities that were not associated with Bell's palsy, such as maxillary or ethmoid sinusitis.

\section{Age}

The number of patients between the ages of 1 and 3 years was 39, accounting for 39\% of the total cohort (Fig. 3). We classified the patients into 2 groups based on their average age: patients under 8 years of age ( 55 patients) and patients older than 8 years of age (46 patients). There was no significant difference in sex, site of palsy, severity, and duration of follow-up between these 2 groups. However, the duration from the onset of symptoms to diagnosis was 2.9 days in patients under 8 years and 2 days in patients older than

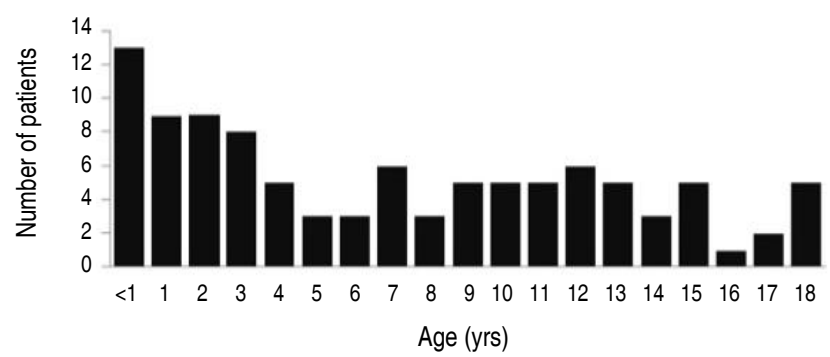

Fig. 3. Age distribution of patients with Bell's palsy.

Table 4. Comparison between patients below and above the age of 8 years

\begin{tabular}{|c|c|c|c|c|}
\hline \multirow[b]{2}{*}{ Variable } & \multirow{2}{*}{$\begin{array}{c}\text { Total } \\
(n=100)\end{array}$} & \multicolumn{2}{|c|}{ Patient age } & \multirow[b]{2}{*}{$P$ value ${ }^{*}$} \\
\hline & & $\begin{array}{c}<8 \mathrm{yr} \\
(\mathrm{n}=54)\end{array}$ & $\begin{array}{c}\geq 8 \mathrm{yr} \\
(\mathrm{n}=46)\end{array}$ & \\
\hline Mean age at diagnosis (yr) & 7.4 & 2.9 & 12.6 & $<0.001$ \\
\hline Female sex, n (\%) & $49(49.0)$ & $25(46.3)$ & $24(52.1)$ & 0.35 \\
\hline Side of palsy & & & & 0.08 \\
\hline Right, n (\%) & $50(50.0)$ & $23(35.8)$ & $27(59.6)$ & 0.08 \\
\hline Mean symptom to diagnosis (day) & 2.5 & 2.9 & 2.0 & 0.03 \\
\hline \multicolumn{5}{|l|}{ Initial severity } \\
\hline$\|$ & 19 & 10 & 9 & 0.55 \\
\hline III & 45 & 23 & 22 & 0.37 \\
\hline IV & 33 & 20 & 13 & 0.24 \\
\hline V & 3 & 1 & 2 & 0.44 \\
\hline Mean duration of follow-up (mo) & 2.0 & 2.1 & 1.8 & 0.58 \\
\hline Mean severity improvement & 2.0 & 2.1 & 2.0 & 0.45 \\
\hline Steroid treatment, n (\%) & $73(73.0)$ & $36(66.7)$ & $37(80.4)$ & 0.09 \\
\hline \multicolumn{5}{|l|}{ Outcome } \\
\hline Good, n (\%) & $94(94.0)$ & $52(96.3)$ & $42(91.3)$ & 0.27 \\
\hline
\end{tabular}

*Fisher exact test or Mann-Whitney test was performed.

8 years $(P=0.03)$ (Table 4$)$. This suggests that children who were 8 years of age or older complained of symptoms themselves; therefore, the duration between symptom onset and hospital visit was shorter. Severity improvement was 2.1 in the patients under 8 years and 2.0 in those who were 8 years of age or older. Good outcomes were observed in 52 of 54 patients (96.3\%) under 8 years. There was no significant difference between the 2 groups $(P=0.27)$.

\section{Prognosis}

The average interval from the first symptom to the hospital visit was 2.5 days in group 1 and 2.6 days in group $2(P=0.69)$. There was no significant difference in age and severity between the groups at the time of diagnosis. In group 1, 78 patients (93.2\%) had a good outcome, 4 patients (5.5\%) remained with grade II or III, and 1 patient (1\%) maintained the grade V status. In group 2, 26 patients (96.3\%) had normal facial nerve function, and only 1 patient remained with grade III. Thus, a total of 94 patients (94\%) showed complete recovery with or without steroid treatment. 


\section{Discussion}

Bell's palsy is an acute and idiopathic peripheral facial nerve palsy that affects facial expressions. As this disorder is a diagnosis of exclusion, other etiologies for facial paralysis should be considered. In children, differential diagnosis of facial palsy includes congenital causes and acquired causes, such as trauma, infection, and neoplasm. ${ }^{7,8)}$ In previous studies explained that there is no evidence of an increased risk of Bell's palsy following immunization with any vaccine. ${ }^{9)}$ In our study, we could not describe the causal relationship between vaccination and Bell's palsy.

Chen and Wong ${ }^{10)}$ showed that the mean age of Bell's palsy onset in children was 6 years 7 months, 52\% of patients were male, and that $44.4 \%$ of patients had right-sided Bell's palsy. In another study, Arican et al. ${ }^{11)}$ reported that the mean age of Bell's palsy onset was 11 years, 59\% of patients were female, and that $47 \%$ of patients had right-sided Bell's palsy. In our study, the mean age of Bell's palsy onset was 7 years 4 months, 50\% of patients were female, and 49\% of patients showed right-sided Bell's palsy.

Most cases of Bell's palsy resolve spontaneously. Management aims to minimize the possibility of incomplete resolution and reduce the risk of morbid sequelae, which include moderate to severe facial weakness, synkinesis, autonomic dysfunction, and contracture of the facial tissues. ${ }^{12)}$ Current management of peripheral facial palsy is based on 4 treatment combinations: steroids alone, antiviral agents alone, a combination of steroids and antiviral agents, or conservative treatment without steroids or antiviral agents.

Bell's palsy is associated with significant edema and ischemia of the facial nerve as it passes through its bony canal. Corticosteroid, the most commonly used agent, seems to reduce inflammation and edema in the nerve sheath. ${ }^{13,14)}$ Steroidal treatment for Bell's palsy has been evaluated extensively over the years; studies have found conflicting results. A large, randomized, controlled trial conducted for verifying the efficacy of steroid treatment for Bell' palsy in adults showed a generally favorable outcome in patients receiving double placebo, with $64.7 \%$ of patients showing full recovery at 3 months and $85.2 \%$ at 9 months. ${ }^{5)}$ This study provided evidence that the early (within 72 hours after symptom onset) administration of oral prednisolone in adult patients with Bell's palsy is effective. De Diego et al. ${ }^{15)}$ conducted a randomized controlled trial and showed that patients treated with prednisolone showed better complete recovery rates than did those treated without steroids.

The treatment of Bell's palsy in children remains controversial. Currently, there is a significant gap in evidence, and no clear-cut guidelines for the management of Bell's palsy in children exist, ${ }^{16}$ ) because the majority of studies are conducted among adults or mixed populations (adults and children combined). Since Bell's palsy has a spontaneous recovery rate of up to $97 \%$ in children, it is difficult to prove the efficacy of steroid administration, as opposed to adults in who complete recovery has been reported for about
$80 \%$ of patients. ${ }^{1,17)}$ Unüvar et al. ${ }^{18)}$ examined 42 children with Bell's palsy treated with methylprednisolone, and compared them to an untreated group. Both groups showed complete recovery after 12 months, and there was no significant difference in recovery between the groups. Another prospective study of children $<15$ years of age from Germany showed a recovery rate of $97 \%$ without any use of steroids. ${ }^{1)}$ Unlike this previous study, Arican et al. ${ }^{11)}$ reported that oral corticosteroid was highly effective in the treatment of Bell's palsy in children, even at a dose of $1 \mathrm{mg} / \mathrm{kg} /$ day of oral prednisolone.

In our study, 94 of 100 patients (94\%) with Bell's palsy recovered completely. Seventy-three patients (73\%) were treated with oral prednisolone, and good outcomes were confirmed in 68 of these patients (93.2\%). In comparison, 26 patients (96.3\%) who did not receive oral prednisolone treatment showed good outcomes. There was no significant difference in the recovery rate between the steroid-treated group and nontreated group $(P=0.48)$. These results are meaningful, and support the results of previous studies showing that corticosteroid treatment is not efficacious in children with Bell's palsy. This study has the advantage that the number of patients is higher than that of the previous studies, and that the study has been conducted in one institution.

This present study was subject to the limitation of all retrospective reviews. Because the data were retrospective in nature, the assessment of the House-Brackmann grades was not protocolized, and it was difficult to timely and definitely determines the time to recovery. We believe that future studies should focus on standardizing a treatment plan, including work-up, clinical evaluation scales, treatment options, and follow-up schedules for children with Bell's palsy, in order to achieve a better outcome. Additionally, a prospective study with a larger number of patients is required.

In conclusion, the causes of facial palsy in children are more complicated in this population. Therefore, careful evaluation and differential diagnosis are necessary. Bell's palsy in children showed excellent prognosis with or without corticosteroid treatment, and there was no difference in the prognosis between the treated and the nontreated groups. Steroid therapy in childhood Bell's palsy may not significantly improve the outcome.

\section{Conflicts of interest}

No potential conflict of interest relevant to this article was reported.

\section{Acknowledgments}

This study was supported by the Pusan National University Hospital (2018 research grant). 


\section{References}

1. Jenke AC, Stoek LM, Zilbauer M, Wirth S, Borusiak P. Facial palsy: etiology, outcome and management in children. Eur J Paediatr Neurol 2011;15:209-13.

2. Peitersen E. Bell's palsy: the spontaneous course of 2,500 peripheral facial nerve palsies of different etiologies. Acta Otolaryngol Suppl 2002:4-30.

3. Kanerva M, Nissinen J, Moilanen K, Maki M, Lahdenne P, Pitkaranta A. Microbiologic findings in acute facial palsy in children. Otol Neurotol 2013;34:e82-7.

4. Cope D, Bova R. Steroids in otolaryngology. Laryngoscope 2008;118: 1556-60.

5. Sullivan FM, Swan IR, Donnan PT, Morrison JM, Smith BH, McKinstry B, et al. Early treatment with prednisolone or acyclovir in Bell's palsy. N Engl J Med 2007;357:1598-607.

6. Salinas RA, Alvarez G, Daly F, Ferreira J. Corticosteroids for Bell's palsy (idiopathic facial paralysis). Cochrane Database Syst Rev 2010: CD001942.

7. Grundfast KM, Guarisco JL, Thomsen JR, Koch B. Diverse etiologies of facial paralysis in children. Int J Pediatr Otorhinolaryngol 1990;19: 223-39.

8. Williamson IG, Whelan TR. The clinical problem of Bell's palsy: is treatment with steroids effective? Br J Gen Pract 1996;46:743-7.

9. Rowhani-Rahbar A, Klein NP, Lewis N, Fireman B, Ray P, Rasgon B, et al. Immunization and Bell's palsy in children: a case-centered analysis. Am J Epidemiol 2012;175:878-85.
10. Chen WX, Wong V. Prognosis of Bell's palsy in children--analysis of 29 cases. Brain Dev 2005;27:504-8.

11. Arican P, Dundar NO, Gencpinar P, Cavusoglu D. Efficacy of lowdose corticosteroid therapy versus high-dose corticosteroid therapy in Bell's palsy in children. J Child Neurol 2017;32:72-5.

12. Holland NJ, Weiner GM. Recent developments in Bell's palsy. BMJ 2004;329:553-7.

13. Adour KK, Ruboyianes JM, Von Doersten PG, Byl FM, Trent CS, Quesenberry CP Jr, et al. Bell's palsy treatment with acyclovir and prednisone compared with prednisone alone: a double-blind, randomized, controlled trial. Ann Otol Rhinol Laryngol 1996;105:371-8.

14. Hyden D, Roberg M, Forsberg P, Fridell E, Fryden A, Linde A, et al. Acute "idiopathic" peripheral facial palsy: clinical, serological, and cerebrospinal fluid findings and effects of corticosteroids. Am J Otolaryngol 1993;14:179-86.

15. De Diego JI, Prim MP, De Sarria MJ, Madero R, Gavilan J. Idiopathic facial paralysis: a randomized, prospective, and controlled study using single-dose prednisone versus acyclovir three times daily. Laryngoscope 1998;108:573-5.

16. Youshani AS, Mehta B, Davies K, Beer H, De S. Management of Bell's palsy in children: an audit of current practice, review of the literature and a proposed management algorithm. Emerg Med J 2015;32:27480.

17. Shih WH, Tseng FY, Yeh TH, Hsu CJ, Chen YS. Outcomes of facial palsy in children. Acta Otolaryngol 2009;129:915-20.

18. Unuvar E, Oguz F, Sidal M, Kilic A. Corticosteroid treatment of childhood Bell's palsy. Pediatr Neurol 1999;21:814-6. 